\title{
Anorectal manometry in irritable bowel syndrome: differences between diarrhoea and constipation predominant subjects
}

\author{
A Prior, D G Maxton, P J Whorwell
}

\begin{abstract}
Anorectal manometry with balloon distension was performed on 28 patients with diarrhoea predominant irritable bowel syndrome, 27 patients with constipation predominant irritable bowel syndrome and $\mathbf{3 0}$ normal controls. In the diarrhoea predominant group balloon volumes required to perceive the sensations of gas, stool, urgency of defecation and discomfort were significantly lower than in controls or constipation predominant patients $(\mathbf{p}<\mathbf{0 . 0 0 1})$. Diarrhoea predominant patients also had a significantly lower rectal compliance than controls or constipation predominant patients $(p<0.03)$ but showed no difference in motor activity induced by distension. When the constipation predominant patients were compared with controls the only significant difference that emerged was in the volume at which discomfort was perceived. No significant differences between constipated subjects and controls were found in the distension induced motor activity. Symptom severity and psychological parameters were also recorded and the diarrhoea predominant patients were found to be more anxious than those with constipation $(p=0.04)$. It proved possible (by comparison with the control group) to identify three abnormal rectal subtypes in patients with irritable bowel syndrome. These were a sensitive rectum (low sensation thresholds, normal or low rectal pressure), a stiff rectum (normal or low sensation thresholds, high pressure) and an insensitive rectum (high sensation thresholds, normal or high pressure) and their distribution varied considerably depending on bowel habit. Some form of rectal abnormality was identified in $75 \%$ of diarrhoea predominant patients compared with $30 \%$ of constipation predominant subjects $(p=0.002)$. A sensitive rectum was a particular feature of diarrhoea predominant patients being observed in $57 \%$ of patients compared with only $7 \%$ of the constipated group $(p<0.001)$.
\end{abstract}

The symptom complex generally accepted as being compatible with the diagnosis of irritable bowel syndrome includes abdominal pain, distension and a disordered bowel habit. Although the pathophysiological mechanisms underlying these symptoms remains poorly understood they may result from disordered colonic function. Patients with irritable bowel syndrome have been shown to exhibit exaggerated sigmoid motor responses to a variety of stimuli, ${ }^{1-3}$ and also to have a lowered visceral sensory threshold to pain caused by balloon distension. ${ }^{+5}$ Many subjects with irritable bowel syndrome also experience symptoms suggestive of anorectal dysfunction such as urgency of defecation, frequent passage of small amounts of stool and a sensation of incomplete evacuation. Only one previous study has been published reporting anorectal function in irritable bowel syndrome ${ }^{6}$ in which patients were separated into those with diarrhoea and constipation predominant disease. No clearcut differences between these subgroups were noted particularly with regard to rectal sensitivity. The number of subjects, especially in the diarrhoea group, however, was small and this may have caused unrepresentative results to be obtained.

The aim of the present study therefore was to investigate anorectal function in a large group of patients with irritable bowel syndrome and in particular to identify differences between constipation and diarrhoea predominant forms of the condition. In addition a large control group was studied and all results were compared with psychological variables and symptom severity.

\section{Methods}

\section{PATIENTS}

The study group consisted of 55 patients with irritable bowel syndrome ( 53 women, two men, age range 18-56). Irritable bowel syndrome was defined as the presence of abdominal pain together with abdominal distension and an altered bowel habit. On the basis of a detailed history, supplemented by diary card data, patients were classified as having diarrhoea if they passed frequent loose stools, and constipation if they experienced infrequent passage of stools or passage of pellety stools associated with straining. Of the 55 patients 15 had an alternating bowel habit and these were classified according to their predominant stool abnormality (10 constipation, five diarrhoea). There were no patients with an alternating bowel habit in whom there was not a clear cut predominance of either diarrhoea or constipation. Thus 28 patients were included in the diarrhoea subset and 27 patients in the constipated subset. All patients had experienced symptoms for over 12 months (range one to 30 years) on at least three days per week and were symptomatic at the time of study. The severity of abdominal pain, distension and disturbed bowel habit was rated by the patients on a 0-10 scale and then totalled to give a symptom severity score with a maximum of 30 . The control group consisted of 30 women (age range $20-49$ ) in whom irritable bowel syndrome had been excluded by questionnaire. Both irritable 

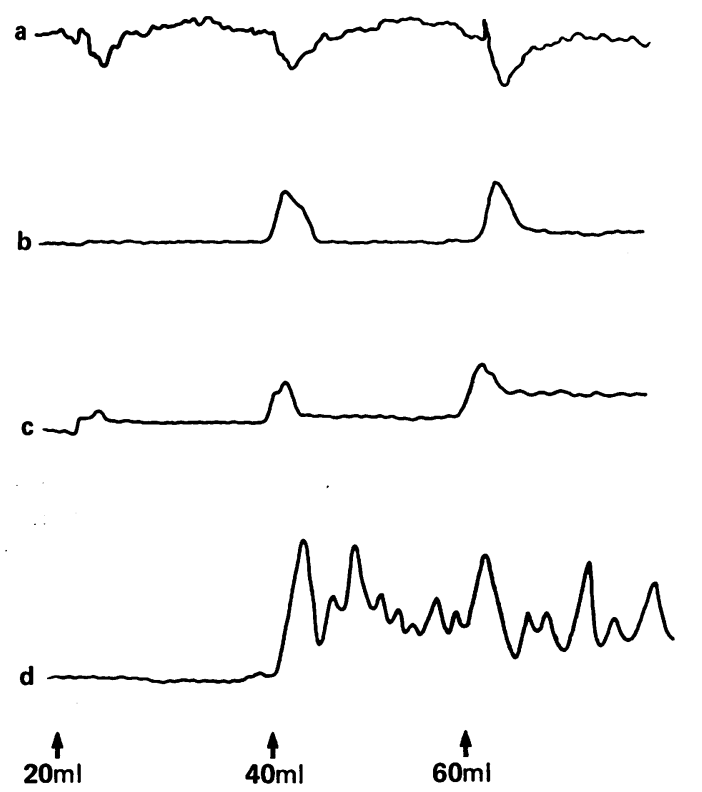

Figure 1: Anorectal response to distension at 40 and $60 \mathrm{ml}$ showing relaxation of the internal anal sphincter (a), single rectal contractions at $4 \mathrm{~cm}$ from the anal verge (b), a stepwise rise in rectal pressure measured in the rectal balloon (c) and repetitive rectal contractions at $14 \mathrm{~cm}$ (d).

bowel syndrome patients and controls also completed the Hospital Anxiety and Depression questionnaire which allows a score to be calculated to detect the presence of abnormal anxiety or depression. $^{7}$

With the subject in the left lateral position a multilumen polyvinyl catheter was placed in the rectum with side holes at 1,4 , and $14 \mathrm{~cm}$ from the anal verge. These were perfused with water at $0.4 \mathrm{ml}$ per minute (Arndorfer Medical Specialities Inc) and connected to water filled transducers. A $5 \mathrm{~cm}$ latex balloon was attached to the catheter between 6 and $11 \mathrm{~cm}$ with a side hole at $8.5 \mathrm{~cm}$ linked to an air filled transducer. Recordings were made on a multichannel pen recorder (Ormed Ltd). After a basal period of at least 15 minutes the rectal balloon was serially inflated with air at intervals of one minute in 20 $\mathrm{ml}$ increments up to $100 \mathrm{ml}$ and then in $50 \mathrm{ml}$ increments to a maximum volume of $500 \mathrm{ml}$.

The anorectal response to distension is shown in Figure 1. When a balloon is inflated in the rectum an initial sharp increase in rectal pressure occurs, which then settles to a new baseline until further distension is undertaken. Balloon inflation may also initiate either single or repetitive rectal contractions. The anal response to rectal distension consists of relaxation of the internal anal sphincter which is initially of short duration but which lengthens as balloon volume increases.

The following measurements were derived from the manometric recordings: (a) The balloon volumes required to elicit sensation of gas, stool, urgency of defecation and discomfort. (b) The intrarectal pressure at each distending volume was calculated by subtracting the pressure measured in the balloon outside the body from that within the balloon when in the rectum. Rectal compliance was calculated from the volume:pressure relationship $(\mathrm{dV} / \mathrm{dP})$ at $100 \mathrm{ml}$. (c) The lowest distending volume required to provoke repetitive rectal contractions. (d) The basal anal pressure and lowest distending volume to initiate internal anal sphincter relaxation and to cause internal anal sphincter relaxation that was sustained throughout the period of distension.

During balloon distension of the rectum it was also noted that irritable bowel syndrome patients exhibited much more variability in the rectal pressures generated compared with the normal subjects. Some patients showed a rapid rise in rectal pressure with stepwise inflation, whereas in others a slow increase in pressure occurred. The volumes required to produce the various rectal sensations also varied greatly. In order to classify the rectal responses to distension, normal ranges for rectal pressure at each distending volume and for volumes required to elicit the sensations of gas, stool, urgency, and discomfort were calculated from the mean values in the control group plus or minus two standard deviations. Irritable bowel syndrome subjects were then classified into one of the following groups: (a) A normal rectum (within the normal range for rectal pressure and volumes to produce rectal senasations). (b) A sensitive rectum (more than 2 standard deviations below the control group mean for volumes to produce at least three of the four rectal sensations recorded but with normal or low rectal pressure). (c) A stiff rectum (more than 2 standard deviations above the control group mean for rectal pressure measured at four distending volumes but with normal or low volumes to produce rectal sensations). (d) An insensitive rectum (more than 2 standard deviations above the control group mean for volumes to produce at least three of the four rectal sensations recorded but with normal or high rectal pressure). (e) A lax rectum (more than 2 standard deviations below the control group mean for rectal pressure measured at four distending volumes but with normal or high volumes to produce rectal sensations).

In order to assess the reproducibility of the anorectal responses to distension manometry was repeated in 40 of the 55 patients at an interval of between 2 and 12 weeks after the initial study. No significant differences in rectal sensitivity or rectal pressure were found and in no patient was there a change in rectal subtype with time.

The data obtained were expressed as either means with their $95 \%$ confidence intervals or group frequencies. A number of the continuous variables (including all the manometric data) were found to have a positively skewed distribution and these were converted to natural logarithms for analysis. Group comparisons were performed using either the Student's $t$ test or contingency table analysis (with Yates's correction) as appropriate.

\section{Results}

Patients' characteristics are summarised in Table I. It can be seen that the patients with irritable bowel syndrome were slightly older than controls (34 years $v 28$ years) although within the irritable bowel syndrome group patients with diarrhoea and constipation were similar in terms of age, symptom severity and length of history. Thirty one of the $55(56.4 \%)$ irritable bowel syndrome patients were found to score positively 
TABLE I Patient characteristics in irritable bowel syndrome and control groups

\begin{tabular}{|c|c|c|c|}
\hline & \multicolumn{2}{|c|}{ Irritable bowel syndrome } & \multirow[b]{2}{*}{$\begin{array}{l}\text { Control } \\
\text { mean } \\
(95 \% C I)\end{array}$} \\
\hline & $\begin{array}{l}\text { Diarrhoea } \\
\text { mean } \\
(95 \% C I)\end{array}$ & $\begin{array}{l}\text { Constipation } \\
\text { mean } \\
(95 \% \text { CI })\end{array}$ & \\
\hline $\begin{array}{l}\text { n } \\
\text { Age (yrs) }\end{array}$ & $\begin{array}{l}28 \\
32 \cdot 6 \\
(28 \cdot 6-36 \cdot 6)\end{array}$ & $\begin{array}{l}27 \\
36 \cdot 3 \\
(32 \cdot 0-40 \cdot 5)\end{array}$ & $\begin{array}{l}30 \\
27 \cdot 6^{\star} \\
(24 \cdot 5-30 \cdot 7)\end{array}$ \\
\hline $\begin{array}{l}\text { Symptom severity } \\
\text { (max score } 30)\end{array}$ & $\begin{array}{l}20 \cdot 0 \\
(18 \cdot 7-21 \cdot 4)\end{array}$ & $\begin{array}{l}20 \cdot 3 \\
(19 \cdot 0-23 \cdot 2)\end{array}$ & - \\
\hline $\begin{array}{l}\text { History length } \\
\text { (yrs) }\end{array}$ & $\begin{array}{l}7 \cdot 5 \\
(4 \cdot 9-10 \cdot 1)\end{array}$ & $\begin{array}{l}7 \cdot 2 \\
(6 \cdot 2-8 \cdot 2)\end{array}$ & - \\
\hline $\begin{array}{l}\text { Psychopathology } \\
\text { Anxiety n (\%) } \\
\text { Depression n (\%) }\end{array}$ & $\begin{array}{r}19(63 \cdot 3) \\
8(26 \cdot 6)\end{array}$ & $\begin{array}{c}10(40) \dagger \\
5(20)\end{array}$ & $\begin{array}{l}0 \\
0\end{array}$ \\
\hline
\end{tabular}

${ }^{\star} \mathrm{p}<0.05$ controls compared with diarrhoea and constipation predominant irritable bowel syndrome; $t \mathrm{p}=0.04$ diarrhoea $v$ predominant irritable bowel syndrome; $\mathrm{tp}=0.04$ dia
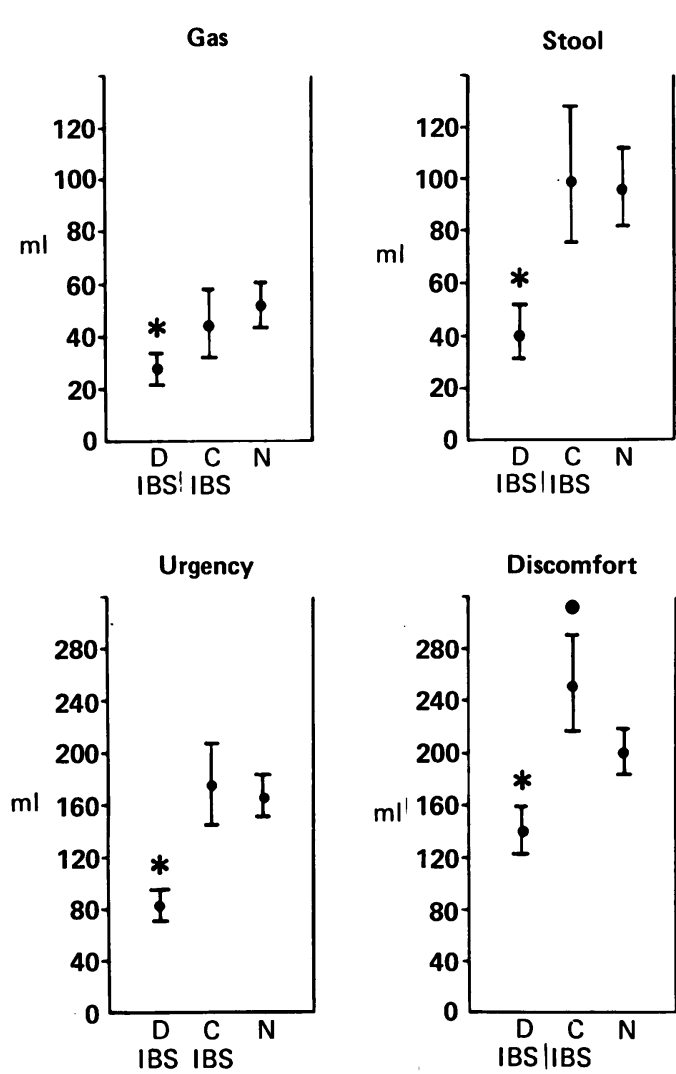

Figure 2: Comparison of rectal sensory thresholds for diarrhoea predominant irritable bowel syndrome, constipation predominant irritable bowel syndrome and normal controls.

DIBS: diarrhoea predominant IBS

CIBS: constipation predominant IBS $\mathrm{N}$ : normal

* $p<0.001$ for DIBS $v$ CIBS and controls $\mathrm{p}<0.05$ for CIBS $v$ controls

TABLE II Rectal and anal characteristics of irritable bowel syndrome patients and controls

\begin{tabular}{|c|c|c|c|}
\hline & \multicolumn{2}{|c|}{ Irritable bowel syndrome } & \multirow{2}{*}{$\begin{array}{l}\text { Control } \\
\text { mean } \\
(95 \% \text { CI })\end{array}$} \\
\hline & $\begin{array}{l}\text { Diarrhoea } \\
\text { mean }(95 \% \text { CI) }\end{array}$ & $\begin{array}{l}\text { Constipation } \\
\text { mean }(95 \% \text { CI) }\end{array}$ & \\
\hline \multicolumn{4}{|l|}{ Sensation (ml) } \\
\hline Gas & $28(22-34)^{\star}$ & $44(33-58)$ & $52(44-61)$ \\
\hline Stool & $40(31-52)^{\star}$ & $99(76-128)$ & $96(82-113)$ \\
\hline Urgency & $84(74-95)^{\star}$ & $174(146-206)$ & $166(151-183)$ \\
\hline Discomfort & $140(123-158)^{\star}$ & $251(216-292) \ddagger$ & $200(183-219)$ \\
\hline Compliance $\left(\mathrm{ml} / \mathrm{cm} \mathrm{H}_{2} \mathrm{O}\right)$ & $5 \cdot 4(4 \cdot 6-6 \cdot 5) \dagger$ & $7 \cdot 2(6 \cdot 0-8 \cdot 7)$ & $7 \cdot 3(6 \cdot 1-8 \cdot 7)$ \\
\hline \multicolumn{4}{|l|}{ Motor activity } \\
\hline Repetitive contractions (n) (\%) & $21(75)$ & $15(57)$ & $15(50)$ \\
\hline Vol to initiate repetitive cont $(\mathrm{ml})$ & $70(52-94)$ & $131(96-178) \ddagger$ & $91(68-121)$ \\
\hline \multicolumn{4}{|l|}{ Anal parameters } \\
\hline $\begin{array}{l}\text { Basal pressure }\left(\mathrm{cm} \mathrm{H}_{2} \mathrm{O}\right) \\
\text { Vol to initiate IAS relaxation }(\mathrm{ml})\end{array}$ & $\begin{array}{l}75(65-87) \\
25(21-29)\end{array}$ & $\begin{array}{l}63(54-74) \\
29(24-37)\end{array}$ & $\begin{array}{l}70(61-80) \\
23(20-27)\end{array}$ \\
\hline Vol for sustained IAS relaxation (ml) & $96(76-121)$ & $164(129-209) \dagger$ & $123(98-153)$ \\
\hline
\end{tabular}

${ }^{\star} \mathrm{p}<0.001$ for diarrhoea predominant $v$ constipation predominant and controls; $+\mathrm{p}<0.05$ for diarrhoea predominant $v$ constipation predominant and controls; $\ddagger p<0.05$ for constipation predominant patients $v$ controls. for anxiety and/or depression on the HAD questionnaire. The number of depressed subjects was similar in those with diarrhoea and constipation, but a higher proportion of diarrhoea subjects scored positively for anxiety $(p=0.04)$. No control subjects were found to be anxious or depressed (Table I).

Significant differences emerged in rectal sensitivity between the study groups (Fig 2). Patients with diarrhoea predominant irritable bowel syndrome perceived the sensations of gas, stool, urgency and discomfort at significantly lower volumes than either the constipated patients $(\mathrm{p}<0.001)$ or controls $(\mathrm{p}<0.01)$. There were no significant differences in rectal sensitivity between the controls and constipated patients except for the volume to elicit discomfort, where constipated subjects tolerated a significantly greater volume $(p=0 \cdot 01)$ (Table II). Patients with diarrhoea predominant irritable bowel syndrome were also found to have a lower rectal compliance than constipated irritable bowel syndrome $(p=0.03)$ or controls $(p=0.02)$. There was no difference in rectal compliance when controls and constipated irritable bowel syndrome patients were compared (Table II).

Repetitive rectal motor activity induced by balloon distension occurred in $50 \%$ of normal subjects and $56 \%$ of constipated patients $(p=n s)$. Although the incidence of repetitive activity was more in diarrhoea predominant irritable bowel syndrome $(75 \%)$ this failed to reach statistical significance $(p=0 \cdot 08)$. The volume required to elicit repetitive contractions was much less in diarrhoea predominant $v$ constipation predominant subjects $(p<0.01)$ but did not statistically differ from that in the control group. No difference in the frequency of contractions induced by rectal distension was found between diarrhoea predominant irritable bowel syndrome, constipation predominant irritable bowel syndrome and controls. In all groups the most common contraction frequency was noted to be between five to 10 per minute.

Basal anal canal pressure and the rectal volume required to initiate relaxation of the internal anal sphincter were similar in controls and diarrhoea and constipation predominant irritable bowel syndrome. Patients with constipation predominant irritable bowel syndrome, however, required larger volumes $(p=0.02)$ in order to produce sustained internal anal sphincter relaxation than either controls or diarrhoea predominant irritable bowel syndrome patients.

The results of subdivision of the irritable bowel syndrome patients dependent on rectal sensitivity and pressure characteristics in comparison to the control subjects (see Methods) is shown in Table III. Of the 28 patients with diarrhoea 16 were found to have a sensitive rectum (12 abnormal for all four rectal sensations, four abnormal for three of the four rectal sensations), five had a stiff rectum and seven were normal. In contrast, abnormalities were noted in a much smaller proportion of the 27 constipated patients. Nineteen patients had normal rectums, five an insensitive rectum, two a sensitive rectum (for all sensations) and one a stiff rectum (Table III). No constipated patients were found to have a lax rectum. As the number 
TABLE III Rectal subtypes in irritable bowel syndrome patients

\begin{tabular}{|c|c|c|c|c|c|c|}
\hline & $n(\%)$ & Age (yr) & $\begin{array}{l}\text { History } \\
\text { length } \\
(y r)\end{array}$ & $\begin{array}{l}\text { Symptom } \\
\text { severity } \\
(\max 30)\end{array}$ & $\underset{(n)}{\text { Anxiety }}$ & $\begin{array}{l}\text { Depression } \\
(n)\end{array}$ \\
\hline \multicolumn{7}{|l|}{ Diarrhoea } \\
\hline Normal & $7(25)$ & $30 \cdot 8$ & 3.0 & $21 \cdot 6$ & 2 & 1 \\
\hline Sensitive & $16(57)$ & $33 \cdot 3$ & $4 \cdot 6$ & $19 \cdot 4$ & 10 & 4 \\
\hline Stiff & $5(18)$ & $32 \cdot 0$ & $12 \cdot 9 \star$ & $20 \cdot 3$ & 4 & 2 \\
\hline \multicolumn{7}{|l|}{ Constipation } \\
\hline Normal & $19(70)$ & $36 \cdot 1$ & $8 \cdot 3$ & $20 \cdot 0$ & 6 & 5 \\
\hline Sensitive & $2(7)$ & $39 \cdot 5$ & $13 \cdot 5$ & $22 \cdot 5$ & 2 & 0 \\
\hline Stiff & $1(4)$ & $21 \cdot 0$ & $5 \cdot 0$ & $18 \cdot 0$ & 0 & 0 \\
\hline Insensitive & $5(19)$ & $34 \cdot 4$ & $7 \cdot 3$ & $22 \cdot 6$ & 2 & 0 \\
\hline
\end{tabular}

${ }^{\star} \mathrm{p}<0.01$ for stiff rectum $v$ normal or sensitive rectum.

of patients with these rectal subtypes was small, meaningful comparison of patient characteristics between these groups was difficult. There was no difference in mean age, symptom severity or prevalence of psychopathology between rectal subtypes. The only difference that emerged was that in diarrhoea patients with a stiff rectum there was a longer history of abdominal symptoms than in those with normal or sensitive rectums $(\mathrm{p}<0.01)$.

\section{Discussion}

This study suggests that when group comparisons are made anorectal function is abnormal in diarrhoea predominant irritable bowel syndrome, whereas a group of subjects with constipation predominant irritable bowel syndrome do not differ significantly from controls. After delineation of a normal range for rectal sensitivity and pressure during distension in controls, however, it is possible to identify individual subjects with reproducible abnormal rectal subtypes in both diarrhoea and constipation predominant irritable bowel syndrome.

Only one previous study has been published in which anorectal manometry with balloon distension was used to identify differences between diarrhoea and constipation predominant irritable bowel syndrome. ${ }^{6}$ In this study the two groups could be separated only on the basis of the frequency of contractions induced by distension. Their observation that patients with diarrhoea predominant irritable bowel syndrome showed a higher incidence of six/minute activity has, however, proved difficult to reproduce ${ }^{8}$ Our study also failed to confirm this observation and could not separate patients with diarrhoea or constipation predominant disease on the basis of any other parameter of distension induced motor activity. In contrast with the previous study, however, differences between the bowel habit types did emerge with regard to rectal sensory thresholds and rectal compliance. Patients with diarrhoea perceived the sensations of gas, stool, urgency and discomfort at much lower balloon volumes than those with constipation and were also found to have a significantly lower rectal compliance. The discrepancy in sensory findings and compliance between the two studies may be a result of sampling error within the diarrhoea predominant population in the previous study as only five subjects were included in this group compared with 28 in the present study.

Anorectal manometry with balloon distension has previously been used to study patients with constipation. ${ }^{9-11}$ Patients with painful constipation, who would fit our criteria for irritable bowel syndrome, were found to have rectal sensory thresholds for sensation, defecation and discomfort similar to normal subjects. ${ }^{9}$ Our results in constipated subjects are generally in accord with these findings differing only in that an increased threshold for the sensation of discomfort was found. In patients with a megarectum others have shown an increased rectal sensory threshold for initial sensation and decreased elasticity of the rectal wall." Five patients with constipation were found to have an insensitive rectum in the present study although the rectal wall pressures generated were normal. They did not, therefore, match the manometric findings previously reported as being consistent with a megarectum, and none had radiological evidence of a megarectum. The variable manometric findings in patients with different forms of constipation emphasises the importance of defining study populations with care.

In the present study $56 \%$ of the total irritable bowel syndrome population had detectable psychopathology, a figure similar to that noted previously. ${ }^{12-13}$ An association was found between psychopathology and bowel habit in that anxiety was significantly more common in patients with diarrhoea, although the incidence of depression was similar in subjects with diarrhoea and constipation predominant irritable bowel syndrome. As the incidence of abnormal rectal subtypes was more common in the diarrhoea predominant subjects it is possible that there may be an association between abnormal rectal response and anxiety. A study seeking such an association, however, would require a very large initial patient population in order to identify sufficient numbers of subjects with each of the various rectal subtypes. It is of interest that a previous study of colonic motility, rather than anorectal function, suggested that the abnormalities noted in irritable bowel syndrome subjects reflected psychoneuroticism rather than being specific for irritable bowel syndrome. ${ }^{14}$ It is also possible that the rectal abnormalities noted in the present study occur in other conditions characterised by constipation or diarrhoea, and this warrants further investigation.

In the present study the irritable bowel syndrome patients could be divided into four rectal subtypes (normal, sensitive, stiff, insensitive) depending on their rectal sensitivity and pressure responses to balloon distension. These responses were found to be reproducible and the distribution of the rectal subtypes varied dependent on bowel habit. Twenty five per cent of diarrhoea predominant patients had a normal rectum compared with $75 \%$ of constipation predominant patients, whereas a sensitive rectum was found in $57 \%$ of diarrhoea patients and only $7 \%$ of constipated subjects. The abnormal rectal responses identified in the patients with irritable bowel syndrome might be of interest for a number of reasons. First, it may help in understanding the origins of some of the symptoms of irritable bowel syndrome. Patients with sensitive or stiff rectums might be expected to experience a desire to defecate and urgency when only small volumes of stool are present. In patients with semisolid 
stool this would lead to the clinical picture often seen in diarrhoea predominant irritable bowel syndrome of frequent defecation and urgency with only small total volumes. In patients with solid stool small pieces would produce the desire to defecate yet are known to be more difficult to expel. ${ }^{\text {is }}$ This would lead to the clinical picture seen in some patients with constipation, who experience a frequent desire to defecate but have to strain excessively to produce small pellets, and then feel a sensation of incomplete evacuation. Second, the abnormal rectal responses identified here may be useful in understanding the pathophysiology of irritable bowel syndrome. Abnormalities of both visceral sensitivity ${ }^{+}$and small bowel ${ }^{16-18}$ and colonic motor activity ${ }^{1-3}$ have previously been described in some patients with irritable bowel syndrome. As these studies have been performed on separate groups of patients, however, it is not clear whether sensory and motor abnormalities tend to coexist in irritable bowel syndrome or whether one abnormality predominates in any particular patient. It remains to be determined whether there is an association between the different rectal responses noted in the present study and a particular pattern of sensory or motor responses elsewhere in the gut. For instance, patients with a sensitive rectum may have visceral hypersensitivity throughout the gut, whilst those with normal rectal sensation may exhibit abnormalities of transit or motor activity elsewhere.

The present study has therefore demonstrated that differences can be shown between diarrhoea and constipation predominant irritable bowel syndrome using anorectal manometry. The abnormalities in rectal response identified using this technique may prove useful in furthering our understanding of the pathophysiology and origin of symptoms in irritable bowel syndrome and enable more rational targeting of therapeutic intervention.

1 Chaudhary NA, Truelove SC. Human colonic motility: a comparative study of normal subjects, patients with ulcerative colitis, and patients with the irritable bowel syndrome. Gastroenterology 1961; 40: 18-26.

2 Harvey RF, Read AE. Effect of cholecystokinin on colonic motility and symptoms in patients with the irritable bowe syndrome. Lancet 1973; i: 1-3.

3 Sullivan MA, Cohen S, Snape WJ. Colonic myoelectrical activity in the irritable bowel syndrome: effect of eating and anticholinergics. N Engl f Med 1978; 298: 878-83.

4 Ritchie J. Pain from distension of the pelvic colon by inflating a balloon in the irritable bowel syndrome. Gut 1973; 14: 125 32 .

5 Kullman G, Fielding JF. Rectal distensibility in the irritable bowel syndrome. Ir Med F 1981; 74: 140-2.

6 Whitehead WE, Engel BT, Schuster MM. Irritable bowel syndrome: physiological and psychological differences between diarrhoea-predominant and constipation-predominant patients. Dig Dis Sci 1980; 25: 404-13

7 Zigmond AS, Snaith RP. The hospital anxiety and depression scale. Acta Psychiatr Scand 1983; 67: 361-70.

8 Schuster MM. Anorectal disorder in the irritable bowe syndrome. Pp 191-202 in Read NW, ed. Irritable bowel syndrome. New York: Grune and Stratton, 1985

9 Lafranchi GA, Bazzoichi G, Brignola C, Camperi M, Labo G Different patterns of intestinal transit time and anorectal motility in painful and painless constipation. Gut 1984; 25: motility

10 Read NW, Timms JM, Barfield LJ, Donnelly TC, Bannister JJ. Impairment of defaecation in young women with sever constipation. Gastroenterology 1986; 90: 53-60.

11 Verduron A, Devroede G, Bouchoucha M, et al. Megarectum Dig Dis Sci 1988; 33: 1164-74.

12 Young J, Alpers DH, Norland MS, Woodruff RA. Psychiatric illness and the irritable bowel syndrome. Practical implications for the primary physician. Gastroenterology 1981; 80 1068-9.

13 Hislop IG. Psychological significance of the irritable colon syndrome. Gut 1971; 12: 452-7.

14 Latimer P, Sarna S, Campbell D, Latimer M, Waterfall W, Daniel EE. Colonic motor and myoelectrical activity: a comparative study of normal subjects, psychoneurotic a comparative study of normal subjects, psychoneurotic patients and patients with the ir
Gastroenterology 1982; 80: 893-901.

15 Bannister JJ, Davison P, Timms JM, Gibbons CG, Read NW Effect of stool size and consistency on defaecation. Gut 1987 28: $1246-50$.

16 Kumar D, Wingate DL. The irritable bowel syndrome: a paroxysmal motor disorder. Lancet 1985; ii: $973-7$.

17 Kellow JE, Phillips SF. Altered small bowel motility in the irritable bowel syndrome is correlated with symptoms. Gastroenterology 1987; 92; 1885-93.

18 Kellow JE, Phillips SF, Miller LJ, Zinsmeister AR. Dysmotility of the small intestine in irritable bowel syndrome. Gut 1988; 29: 1236-43. 